\title{
Erratum: Stabilizing prospects for a universal flu vaccine
}

\section{Markus Elsner}

Nat. Biotechnol. 33, 1043-1044 (2015); published online 8 October 2015; corrected after print 28 July 2016

In the version of this article initially published, the name and title of the author, Markus Elsner, Senior Editor, was omitted. The error has been corrected in the HTML and PDF versions of the article.

\section{Erratum: Will Europe toast GM wheat for gluten sufferers?}

Lucas Laursen

Nat. Biotechnol. 34, 369-371 (2016); published online 7 April 2016; corrected after print 8 June 2016

In the version of this article initially published, on p.369, "European consumers" were said to account for "over $€ 1.1$ ( $\$ 1.21)$ million" of the "nearly $€ 1.9$ million worldwide gluten-free food market"; in both cases the figure should have been in billions, not millions. In addition, the opening sentence said "This winter," but should have read "Soon," and on p.371, paragraph three, "at a General Mills facility earlier this year," should have read "in 2015." The errors have been corrected in the HTML and PDF versions of the article.

\section{Corrigendum: Secure cloud computing for genomic data}

Somalee Datta, Keith Bettinger \& Michael Snyder

Nat. Biotechnol. 34, 588-591 (2016); published online 9 June 2016; corrected after print 11 August 2016

In the version of this article initially published, the competing financial interests line should have been positive in the HTML as it was in the PDF ("The authors declare competing financial interests"). The statement "M.S. is a co-founder of Personalis and SensOmics and a member of the scientific advisory boards of Personalis, SensOmics and Genapsys" should also have appeared in the HTML. The errors have been corrected in the HTML and PDF versions of the article.

\section{Corrigendum: Genetic improvement of tomato by targeted control of fruit softening}

Selman Uluisik, Natalie H Chapman, Rebecca Smith, Mervin Poole, Gary Adams, Richard B Gillis, Tabot M D Besong, Judith Sheldon, Suzy Stiegelmeyer, Laura Perez, Nurul Samsulrizal, Duoduo Wang, Ian D Fisk, Ni Yang, Charles Baxter, Daniel Rickett, Rupert Fray, Barbara Blanco-Ulate, Ann L T Powell, Stephen E Harding, Jim Craigon, Jocelyn K C Rose, Eric A Fich, Li Sun, David S Domozych, Paul D Fraser, Gregory A Tucker, Don Grierson \& Graham B Seymour Nat. Biotechnol. 34, 950-952 (2016); published online 25 July 2016; corrected after print 14 September 2016

In the version of this article initially published, the volume and page numbers for reference 46 were incorrect. The error has been corrected in the HTML and PDF versions of the article 